\title{
Effects of transportation and storage duration of Japanese quail eggs on hatchability
}

\author{
G. Çopur Akpınar ${ }^{1 \#}$ \& A. Günenç ${ }^{2}$ \\ ${ }^{1}$ Department of Animal Science, Faculty of Agricultural Science, Mustafa Kemal University, Hatay, Turkey \\ ${ }^{2}$ Provincial Directorate of Food, Agriculture and Livestock, Edirne, Turkey
}

(Received 6 June 2018; Accepted 8 November 2018; First published online 9 April 2019)

\author{
Copyright resides with the authors in terms of the Creative Commons Attribution 4.0 South African Licence. \\ See: http://creativecommons.org/licenses/by/4.0/za \\ Condition of use: The user may copy, distribute, transmit and adapt the work, but must recognise the authors and \\ the South African Journal of Animal Science.
}

\begin{abstract}
This study was conducted to investigate the effects of transportation from breeder's farm to hatchery, and of storage duration on the hatchability of quail eggs. Hatching eggs were divided into two groups. The first group was stored for seven days and the second for 14 days. Half of each group was subjected to 200 $\mathrm{km}$ transportation before initiation of embryonic development, and the other half was not transported. Relative weight loss ratios varied significantly with storage duration, but did not vary after transportation. Hatchability of fertile eggs varied with storage duration and transportation, but only the effects of storage $x$ transportation were found to be significant. Embryonic mortality for the first period of 14-day storage (22.1\%) was significantly higher than those stored for seven days. In the second period (days 10 - 16), embryonic mortality ratios varied significantly with storage and transportation. Transportation after 7-day storage influenced the hatchability of fertile eggs negatively, compared with non-transported eggs stored for seven days. On the other hand, transportation after long-term storage had a higher hatchability of the fertile eggs than the non-transported eggs stored for the long time. These findings suggest that the vibration through transportation over the secondary road after long-term storage influenced the embryonic development of hatching eggs positively. Thus, the discarded chick ratio of the long-term + transport group was lower than short-term + transport group, and improved the hatchability of fertile eggs.
\end{abstract}

Keywords: discarded chick, hatchability of fertile eggs, relative weight loss

${ }^{\#}$ Corresponding author: gulsenankara@gmail.com

\section{Introduction}

The hatching egg quality of quails (Coturnix coturnix japonica) is greatly influenced by breeder age and egg storage (Nowaczewski et al., 2010). With prolonged storage, hatching performance and power decrease (Sreenivasaiah \& Ramappa, 1985; Seker et al., 2005; Romao et al., 2008; Dereli-Fidan et al., 2012; Othman et al., 2014), and early, mid and late embryonic mortalities increase significantly (Seker et al., 2005; Dereli-Fidan et al., 2012). Egg weight loss ratios also increase throughout the storage period (Petek \& Dikmen, 2004; Lacin et al., 2008; Dudusola, 2009; Baylan et al., 2011). It has been reported that quail eggs could preserve the desired quality attributes for storage periods shorter than four days (Dudusola, 2009).

Breeder farms are usually located far from hatcheries. The transportation distances of hatching eggs, along with the other factors, may result in significant losses in yield and productivity level. Although airline transportation of hatching eggs from breeder farms to hatcheries is increasing, road transport is still common. Moreover, hatching eggs are subjected to serious losses in quality in airline transport because of delays and custom processes (Anonymous, 2016).

Embryos and hatched chicks have undeveloped locomotive and sensual organs compared with developed individuals of the later stages. Therefore, they are susceptible to hazardous and variable conditions (Mukai et al., 2014). Embryo, the living material of the hatching egg (at gastrula stage with 20000 - 40000 cells), is highly sensitive to vibration and excess temperatures (Butcher \& Nilipour, 2016).

High-quality, perfect hatching eggs free of defects are the primary target of breeders. However, transportation over rough roads with inexperienced drivers, poor vehicle suspension and inadequate ventilation in the vehicles can result in serious economic losses (Butcher \& Nilipour, 2016). Thus, various 
transportation factors have negative impacts on poultry production. These include temperature, humidity, ventilation, gas exchange, transportation intensity, road conditions, characteristics of transport vehicle, driver performance and mechanical vibration (Mitchell \& Kettlewell, 1998; Schwartzkopf-Genswein et al., 2012). Racine (2013) indicated that the vibration of the eggs and exposure to toxic impacts increased malformation ratios (pre-mature chicks).

Egg quality is influenced significantly by vibration through transportation, road quality, distance, driving speed, size of load, suspension system and number of axles of the vehicle (Singh, 1991; Pierce et al., 1992). Vibration is the primary reason for damage to fertile eggs and stress in day-old chicks and broiler hens.

Mechanical vibration causes stress and losses in hatching outcomes in particular and ultimately in production. However, transportation of hatching eggs and chicks is an essential process of poultry operations. Since it is hard to control the roads and transportation vehicles, road- and vehicle-induced vibration may be harmful to the developing embryo (Mohammadzadeh et al., 2015). According to Tullett (2009), hatching eggs that are subjected to excessive coarse processes or vibration during collection and transportation had higher malformation ratios (extra legs and wings in embryos). According to Torma \& Kovascne (2012), such factors resulted in malformations such as an extra leg, or face duplication.

Several studies have investigated the effects of transportation and the other mechanical impacts on commercial egg quality. However, the effects of such factors on hatching eggs were investigated in a limited number of studies. This study therefore was conducted to investigate the effects of transportation and duration of storage on the hatching outcome of quail eggs.

\section{Material and Methods}

Hatching eggs of 24-week-old quails from a commercial breeding farm in Adana constituted the experimental material of the present study. Eggs were collected over three days. The eggs were numbered individually and weighed before storage. Then, the eggs were allocated randomly to 7- and 14-day storage groups. Each storage period had 5 replications with 100 eggs in each replicate $(5 \times 100 \times 2$; $2 \times 7$ - and 14-day storage periods, 5 replications/tray, 100 eggs in each replicate). Each storage period had 1000 eggs, thus 2000 eggs were used in experiments. Following storage (7 and 14 days), half of the eggs (1000 eggs) were transported $200 \mathrm{~km}$ over a secondary road, and then incubated. Eggs were transported in air-conditioned vehicles at $18{ }^{\circ} \mathrm{C}$ temperature. The other half of the eggs were not transported and were incubated directly after storage. For incubation, setter and hatcher machines were used with a 1280 poultryegg capacity (Çimuka). Temperature and relative humidity were $37.6{ }^{\circ} \mathrm{C}$ and $60 \%-65 \%$ in the setter, respectively, while in the hatcher, the temperature and humidity were adjusted to $37.2{ }^{\circ} \mathrm{C}$ and $65 \%-70 \%$, respectively.

After incubation, healthy hatched marketable and discarded chicks were recorded. In the treatment groups, only non-walking discarded chicks were determined. No chicks were found in the discards with problems such as umbilicus incompletely closed navel, red hocks, crossed beak, lack of eyes and malformation (Tullet, 2009).

Unhatched eggs were broken and subjected to macroscopic assessment to determine stage of embryonic death. Embryonic mortality was classified in accordance with Aygun et al. (2012) as mortality in the first period (1 - 9 days of incubation) (black eye visible and embryo without feathers); second period (10 17 days of incubation) (embryo with feathers and embryo with yolk out); and the third period (17 - 18 days of incubation) (full grown embryo dead and with yolk subtracted) (Aygun et al., 2012). Healthy marketable chicks were weighed individually to determine the effects of storage and transportation on the proportion of chick weight to egg weight.

The experiment was carried out in a $2 \times 2$ factorial design (storage and transportation). All data were analysed using GLM. Duncan's multiple range test was used to compare treatment means. Arcsine transformation was applied to embryonic mortality data to obtain a normal distribution. However, actual means were presented. All statistical analyses were carried out using SPSS 20.

\section{Results and Discussion}

The differences in relative weight loss of the treatment groups throughout storage were found to be significant $(P<0.001)$ (Table 1$)$. This trait varied with storage period, but did not change following transportation. The interaction between storage period and transportation was found to be not significant $(P$ $>0.05$ ).

Lacin et al. (2008) reported that weight loss after 3-, 8- and 14-day storage was $1.44 \%, 1.99 \%$ and $2.56 \%$, respectively. Dudusola (2009) investigated the effects of various storage methods and duration on the quality of quail eggs, and reported weight loss percentages for 4-, 7-, 14- and 21-day storage of 1.2\%, $2.8 \%, 3.9 \%$ and $5.4 \%$, respectively. The weight loss ratios reported for 7 - and 14-day storage were greater than the current findings. Baylan et al. (2011) investigated the effects of selenium supplementation of quail 
rations, storage $\left(15,30\right.$ and 45 days) and temperatures $\left(4{ }^{\circ} \mathrm{C}\right.$ and $\left.20{ }^{\circ} \mathrm{C}\right)$ on egg quality, and reported increasing weight loss ratios with increasing storage. The present findings concur with those earlier ones. In the present study, weight loss ratios for 7- and 14-day storage were similar to those of Aygun \& Sert (2013), who reported weight loss at $1.72 \%$ for 7 -day storage and $2.73 \%$ for 14 -day storage.

Table 1 Effect of storage time and transportation on the percentage egg weight loss

\begin{tabular}{|c|c|c|}
\hline \multicolumn{2}{|c|}{ Treatments } & \multirow{2}{*}{$\begin{array}{c}\bar{X} \pm S \bar{X} \\
(\%)\end{array}$} \\
\hline Storage duration (day) & Transportation (km) & \\
\hline \multirow{2}{*}{7} & 0 & $1.27^{\mathrm{a}} \pm 0.02$ \\
\hline & 200 & $1.23^{a} \pm 0.01$ \\
\hline \multirow{2}{*}{14} & 0 & $2.68^{b} \pm 0.09$ \\
\hline & 200 & $2.77^{\mathrm{b}} \pm 0.05$ \\
\hline
\end{tabular}

Roriz et al. (2016) investigated the effects of various storage durations (1 - 10 days) on weight loss and hatch outcomes, and reported weight loss of $0.97 \%$ for 1 -day storage, $2.8 \%$ for 7 -day storage and $3.26 \%$ for 10-day storage. Fidan (2012) reported weight loss of quail eggs for 5-, 10- and 15-day storage as $0.34 \%, 0.85 \%$ and $1.45 \%$, respectively.

Chick weights were monitored and associated with initial egg weights to express hatchling formation ratios (Table 2). This trait did not vary with treatment groups. Storage duration $x$ transportation interaction was found to be not significant. The average proportion of chick weight to egg weight ratio (Table 2) was within the values reported by Wilson (1991) for chickens, 62\% - 78\%.

Table 2 Effect of storage time and transportation on the chick weight to egg weight ratio

\begin{tabular}{llc}
\hline & Treatments & $\bar{X} \pm S \bar{X}$ \\
\hline Storage duration (day) & Transportation $\mathbf{( k m )}$ & $65.5 \pm 1.17$ \\
\hline 7 & 0 & $64.8 \pm 1.31$ \\
14 & 200 & $66.0 \pm 0.71$ \\
& 0 & $66.2 \pm 0.89$ \\
\hline
\end{tabular}

Uddin et al. (1994) reported that chick weight to egg weight ratios for egg weight groups, light (8.59 g), medium $(9.52 \mathrm{~g})$ and heavy $(10.56 \mathrm{~g})$, were $68.8 \%, 70.3 \%$ and $69.6 \%$, respectively. The present ratios are lower than these. A chick weight to egg weight ratio of $69.9 \%$ was reported by Moraes et al. (2008), as $70.8 \%$ by Genchev (2009), and as 76.4\%, 74.8\% and 70.5\% for egg weight groups of $14.19 \mathrm{~g}, 12.02 \mathrm{~g}$ and $10.20 \mathrm{~g}$, respectively by Sadeghi et al. (2013). Those values were higher than the present findings. On the other hand, for white, black and brown Japanese quail genotypes, Islam et al. (2014) reported chick weight to egg weight ratios of $62.7 \%, 62.9 \%, 58.2 \%$ and $46.4 \%$, which are lower than in the present study. This trait was reported as $66.9 \%$ by Dere et al. (2005); as 64.5\%, 62.8\% and 66.5\% for light (8.91 g), medium (9.80 g) and heavy (10.76 g) egg weight groups, respectively, by Adeyanju et al. (2014) and as 69.4\% by Alasahan et al. (2016).

Hatchability of fertile egg values is presented in Table 3. The highest hatchability of fertile eggs (69.3\%) was obtained from the 7-day storage, non-transported group, followed by the 14-day storage, transported group at 59.6\%, the 7-day stage and transported group at $57.5 \%$, and the 14-day storage and non-transported group at $52.4 \%$. 
Table 3 Effect of storage time and transportation on percentage the hatchability of fertile eggs

\begin{tabular}{llc}
\hline & Treatments & $(\bar{X} \pm S \bar{X})$ \\
\cline { 1 - 2 } Storage duration (day) & Transportation $\mathbf{( k m )}$ & $69.3^{\mathrm{a}} \pm 6.08$ \\
7 & 0 & $57.5^{\mathrm{ab}} \pm 3.47$ \\
& 200 & $52.4^{\mathrm{b}} \pm 2.91$ \\
14 & 0 & $59.6^{\mathrm{ab}} \pm 1.96$ \\
& 200 & \\
\hline $\mathrm{a}, \mathrm{b}$ Differences in means in the same column with different superscripts are significant at $P<0.05$
\end{tabular}

Storage $\mathrm{x}$ transportation interaction was found to be significant $(P<0.05)$. Compared with the 7 -day storage, non-transported group, transportation after 7-day storage had a negative effect on hatchability of fertile eggs. However, the hatchability of fertile eggs of the 14-day storage, transported group was higher than the hatchability of fertile eggs of the non-transported group of the same duration of storage. This indicated that exposure to vibration after long storage might influence embryonic development positively throughout the incubation process. Thus, the discarded chick ratio of 14-day storage, and transported eggs was lower than the discarded egg ratio of 7-day storage non-transported eggs.

Seker et al. (2005) reported that hatchability of fertile eggs for $1-3,4-6,7-9,10-12$ and $13-15$ days' storage was $90.4 \%, 88.7 \%, 68.0 \%, 72.5 \%$ and $50.3 \%$, respectively. Hatchability of fertile eggs was reported as $71.5 \%$ by Daikwo et al. (2011), as $96.1 \%$ and $95.7 \%$ for 22 -week-old light $(7.5-9.5 \mathrm{~g})$ and heavy (9.6 - $12.0 \mathrm{~g}$ ) egg groups, respectively, and as $78.7 \%$ and $66.7 \%$ for the same weight groups of 36 weeks old, respectively, by Dudusola (2013). Premavalli et al. (2016) reported hatchability of fertile eggs as $74.7 \%$ for non-stored eggs and as $62.3 \%$ for 7 -day stored eggs. The present hatching percentage for 7 -day storage (63.4\%) (Table 3) was lower than the value reported by Premavalli et al. (2016).

Torma \& Kovacsne (2012) indicated an about approximately 15\% decrease in the hatchability of the eggs that were exposed to intensive vibration. Researchers reported that the hatchability of fertile eggs of a control, without vibration, and eggs subjected to vibration of between $10 \mathrm{~Hz}$ and $30 \mathrm{~Hz}$ as $61.8 \%$ and $54.5 \%$, respectively. In the same study, the hatchability of fertile eggs that were vibrated at $20 \mathrm{~Hz}$ and $30 \mathrm{~Hz}$ for 10 minutes and the non-vibrated control group were reported as $76.8 \%, 64.9 \%$ and $80.8 \%$, respectively. Researchers indicated that the hatchability of fertile eggs of the control group without vibration was higher than the hatchability of fertile eggs of vibrated eggs at various levels, but the differences between treatment groups were not significant. The present findings are different from the findings of Donofre et al. (2017), which indicated negative influences of excessive vibration on hatching outcome and chick quality of hatchability eggs. This can be explained by the difference in vibration levels that were applied experimentally by Donofre et al. (2017), and the vibration levels from transportation of the eggs in this study. Donofre et al. (2017) applied various mechanical vibration levels artificially for certain durations. They reported the hatchability of fertile eggs at low vibration for short duration, low vibration for long duration, high vibration for short duration, high vibration for long duration and control treatments as $93.7 \%, 94.4 \%, 92.1 \%, 88.9 \%$ and $94.5 \%$, respectively.

In the current study the differences in embryonic mortality in the first period (which covered the $1-9$ days of embryonic development) of the treatment groups were highly significant $(P<0.001)$ (Table 4). The first-period embryonic mortality of the 14-day storage group was higher than the embryonic mortality of the 7-day storage group. The value was recorded as $7.18 \%$ for the non-transported group of 7 -day storage, and as $8.36 \%$ in the 7 -day storage group, but the differences between these two groups were not significant.

The transported present findings indicated that embryonic mortality in the first period was higher after long storage duration than with short storage. Previous studies that investigated the effects of storage duration on hatching parameters, support the current findings. Seker et al. (2005) reported early-period embryonic death ratios of Japanese quail (Coturnix coturnix japonica) for $1-3,7-9$ and 13 - 15 day storage as $5.09 \%, 19.48 \%$ and $19.52 \%$, respectively. In another study carried out with quail, Lacin et al. (2008) reported early-period embryonic mortality for 3-, 8- and 14-day storage as $15.4 \%, 20.0 \%$ and $40.0 \%$, respectively. These values were higher than those reported in the present study for $7-(7.70 \%)$ and 14 (22.09\%) day storage. On the other hand, the first-period embryonic mortalities of the present study were higher than the values reported by Aygun \& Sert (2013) for 7- and 14-day storage of quail eggs, as $2.17 \%$ and $3.76 \%$, respectively. The differences in embryonic mortality ratios were mainly the result of genotypes, ages and processes that were applied in hatching eggs. 
Table 4 Effect of storage time and transportation on percentage the first-period ( 1 - 9 days) embryonic mortality ratio

\begin{tabular}{llc}
\hline & Treatments & $\begin{array}{c}\bar{X} \pm S \bar{X} \\
\mathbf{( \% )}\end{array}$ \\
\hline Storage duration (day) & Transportation $\mathbf{( k m )}$ & $7.18^{\mathrm{a}} \pm 0.86$ \\
7 & 0 & $8.36^{\mathrm{a}} \pm 1.64$ \\
14 & 200 & $23.23^{\mathrm{b}} \pm 2.01$ \\
& 0 & $20.96^{\mathrm{b}} \pm 1.46$
\end{tabular}

a,b Differences in means in the same column with different superscripts are significant at $P<0.05$

Torma \& Kovacsne (2012) reported early embryonic mortalities of hatching eggs that were subjected to vibration between $10 \mathrm{~Hz}$ and $30 \mathrm{~Hz}$ and the control eggs without vibration, as $23.6 \%$ and $18.8 \%$, respectively. This trait was observed as $11.15 \%, 19.52 \%$ and $9.66 \%$ for the eggs subjected to $20 \mathrm{~Hz}$ and 30 $\mathrm{Hz}$ vibration levels for 10 minutes and control eggs without vibration. While the differences between nonvibrated group and $20 \mathrm{~Hz}$ vibration group were not significant, the $30 \mathrm{~Hz}$ vibration group was significantly different from the other treatment groups. In the present study, non-transported and transported groups were not significantly different. This finding partially supports those of Torma \& Kovacsne (2012) but is quite different from those of Shannon et al. (1994), who indicated a 32\% increase in embryonic mortality at 5 - 50 $\mathrm{Hz}$ vibration levels.

The second-period embryonic mortality ratios (covering $10-17$ days of embryonic development) varied with the experimental treatments $(P<0.01)$ (Table 5).

Table 5 Effects of storage time and transportation on the second period (10 - 17 day) embryonic mortality ratio

\begin{tabular}{llc}
\hline & \multicolumn{1}{c}{ Treatments } & $\bar{X} \pm S \bar{X}$ \\
\cline { 1 - 2 } Storage duration (day) & Transportation $\mathbf{( k m )}$ & $2.68^{\mathrm{a}} \pm 0.52$ \\
7 & 0 & $2.13^{\mathrm{a}} \pm 0.98$ \\
& 200 & $7.39^{\mathrm{b}} \pm 0.66$ \\
14 & 0 & $4.13^{\mathrm{a}} \pm 1.09$
\end{tabular}

$\overline{\mathrm{a}, \mathrm{b}}$ Differences in means in the same column with different superscripts are significant at $P<0.05$

With regard to the second-period embryonic mortalities, storage duration $\mathrm{x}$ transportation interaction was found to be not significant. The differences in second-period embryonic mortality of non-transported and transported 7-day stored eggs and transported 14-day stored eggs were also not significant. However, the 14-day stored, non-transported group was significantly different from the other treatments $(P<0.01)$. The present second-period embryonic mortalities for 7- and 14-day storage groups $(2.41 \%$ and $5.76 \%$, respectively) were lower than the values reported by Seker et al. (2005) for $1-3,7-9$ and 13 - 15-day storage $(1.70 \%, 4.14 \%$ and $10.47 \%$, respectively). These differences may have resulted from the period of coverage, since the second-period embryonic mortality of the present study covered $10-17$ days, but covered 8 - 16 days in the other studies. The present second-period embryonic death ratios of 7- (2.4\%) and 14- $(5.76 \%)$ day storage were higher than those reported by Aygün \& Sert (2013) for 7- $(2.18 \%)$ and $14-$ $(2.79 \%)$ day storage. On the other hand, these findings were lower than those reported by Alasahan et al. (2016), who investigated the effects of colour and spot sizes on hatch outcomes of quail eggs $(5.6 \%$ $10.8 \%)$. Average second-period embryonic mortality was $4.08 \%$ in the present study. This value was lower than the value Copur Akpinar et al. (2017) reported for hatching eggs of yellow Japanese quail (12.27\%). 
The second-period embryonic mortality ratios of transported and non-transported eggs were different. Torma \& Kovacsne (2012) reported second-period embryonic death ratios of a vibrated group (subjected to $10-30 \mathrm{~Hz}$ vibration for 10 minutes) and the control (without vibration) as $1.34 \%$ and $0.59 \%$. In the same study, eggs were subjected to $10-30 \mathrm{~Hz}$ vibration for 10 minutes, then stored for three days. The secondperiod embryonic mortality rates of these eggs and control eggs were reported as $0.96 \%$ and $0.61 \%$, respectively. The embryonic mortalities of $20 \mathrm{~Hz}$ and $30 \mathrm{~Hz}$ constant vibration and control groups were reported as $0.39 \%, 1.68 \%$ and $0.56 \%$, respectively. While the differences between the treatments were not significant in the first two trials, and differences between the low vibration and the control group were not significant in the third trial, the high vibration group was significantly different from the others. Significant effects of transportation on the embryonic mortality of the second-period of the present study concur with the findings of Torma \& Kovacsne (2012).

The differences in embryonic mortality in the third period (17 - 18 days of embryonic development) (Table 6) were found to be not significant. Storage $x$ transportation interaction was not significant for this trait.

Table 6 Effect of storage time and transportation on the embryonic mortality of the third period (17 - 18 days) ration

\begin{tabular}{lcc}
\hline & Treatments & $\bar{X} \pm S \bar{X}$ \\
\cline { 1 - 2 } Storage duration (day) & Transportation $\mathbf{( k m )}$ & (\%) \\
\hline 7 & 0 & $7.98 \pm 2.98$ \\
74 & 200 & $4.41 \pm 1.33$ \\
& 0 & $5.82 \pm 1.54$ \\
& 200 & $8.19 \pm 0.54$ \\
\hline
\end{tabular}

The present findings in the third period for embryonic mortality ratios for two storage periods were different from the values that Aygun \& Sert (2013) reported for the same duration, as $1.39 \%$ and 2.195 , and from the findings of Alasahan et al. (2016), who investigated the effects of egg shell colour and spot size on hatching parameters $(1.9 \%$ and $2.9 \%)$. The embryonic mortalities of the present third period were lower than the values of Copur Akpinar et al. (2017) (11.85\%) and those of Lacin et al. (2008), which were reported for 3-, 8- and 14-day storage as $19.2 \%, 31.3 \%$ and $47.5 \%$, respectively. The present findings were also lower than the late embryonic mortality ratios reported by Seker et al. (2005), which were $7-9$ (8.43\%) and $13-15$ days (19.69\%) storage of Japanese quail eggs.

Torma \& Kovacsne (2012) reported that late embryonic mortality ratios did not change in eggs subjected to vibration levels between $10 \mathrm{~Hz}$ and $30 \mathrm{~Hz}$ and stored for three days as well as those subjected to $10-30 \mathrm{~Hz}$ vibration levels, but not stored, and those subjected to $20 \mathrm{~Hz}$ and $30 \mathrm{~Hz}$ constant vibration levels. The present insignificant effects of transportation after 7- and 14-day storage support the findings of Torma \& Kovacsne (2012).

The chicks that completed hatching, but were not able to stand, were classified as discarded hatchlings. Discarded chicks consisted only of the chicks that were not able to stand up fully, since other types of discarded chicks (above) were not encountered. The effects of treatments and storage $x$ transportation interaction were found to be highly significant $(P<0.001)($ Table 7$)$.

With regard to the discarded hatching chick ratio, short-term + transport group (27.57\%) was significantly different from the other groups $(P<0.001)$. The lowest value $(7.13 \%)$ was obtained from the 14-day stored transported group. Vibration during transportation may provide better ambient (for embryonic development) to the embryo of long-term eggs than short-term stored ones. Thus, after-storage transportation was applied to eggs at the same time and in the same way, but the positive impacts on longterm eggs were not observed on short-term eggs.

The present discarded hatched chick ratios were different from the findings of previous studies. In a study that investigated the effects of egg weight and shape index on hatching outcomes, Copur et al. (2010) reported discarded hatched chick ratios for $<13 \mathrm{~g}, 13-14 \mathrm{~g}$ and $>14 \mathrm{~g}$ eggs as $0.78 \%, 0.43 \%$ and $1.85 \%$, respectively. The results were different from the current ones, since the effects of vibration were investigated and only leg problems were considered in this study. 
Table 7 Effect of storage time and transportation on the ratio of discarded chicks

\begin{tabular}{llc}
\hline & Treatments & $\bar{X} \pm S \bar{X}$ \\
\hline Storage duration (day) & Transportation $\mathbf{( k m )}$ & $9.42^{\mathrm{a}} \pm 1.94$ \\
7 & 0 & $27.57^{\mathrm{b}} \pm 3.06$ \\
14 & 200 & $9.28^{\mathrm{a}} \pm 1.64$ \\
& 0 & $7.13^{\mathrm{a}} \pm 1.25$ \\
\hline
\end{tabular}

$\overline{a, b}$ Differences in means in the same column with different superscripts are significant at $P<0.05$

Weight loss throughout incubation influences hatch outcomes directly. Variations in relative weight losses of the experimental groups during the embryonic development $(0-14$ th day) period are provided in Table 8.

Table 8 Effect of storage time and transportation on the weight loss rate during embryonic development

\begin{tabular}{llc}
\hline & Treatments & $\bar{X} \pm S \bar{X}$ \\
\hline Storage duration (day) & Transportation $\mathbf{( k m )}$ & $14.43^{\mathrm{b}} \pm 0.39$ \\
\hline 7 & 0 & $13.98^{\mathrm{ab}} \pm 1.13$ \\
& 200 & $12.36^{\mathrm{a}} \pm 0.19$ \\
14 & 0 & $12.15^{\mathrm{a}} \pm 0.21$ \\
\hline $\mathrm{a}, \mathrm{b}$ Differences in means in the same column with different superscripts are significant at $P<0.05$
\end{tabular}

The differences in relative weight losses of the experimental groups were significant $(P<0.05)$. Storage $\mathrm{x}$ transportation was not significant. Romao et al. (2008) reported weight losses in meat- and eggtype quail eggs during the incubation period as $8.27 \%$ and $9.31 \%$, respectively. Genchev et al. (2009) reported the value as $9.72 \%$ for meat-type Prague quail. Nowaczewski et al. (2010) reported egg weight losses of different weight groups (light: $10.5 \mathrm{~g}$, medium: $10.51-11.50 \mathrm{~g}$, heavy: $11.51-12.50 \mathrm{~g}$ and XL: $12.51 \mathrm{~g}$ ) during the incubation period ( 0 - 15 days) as $11.0 \%, 10.4 \%, 9.9 \%$ and $9.5 \%$, respectively.

The present weight loss ratios were higher than those Nowaczewski et al. (2012) reported for top $(9.07 \%)$, medium (8.94\%) and bottom (8.98\%) egg trays of a setter. The differences may come from the processes applied to eggs since they were placed in the setter without any prior storage. Aygun \& Sert (2013) reported egg weight loss ratios of 7- and 14-day stored eggs during 0 - 14-day incubation as $9.72 \%$ and $9.77 \%$, respectively. Adeyanju et al. (2014) reported weight loss ratios for light $(8.91 \mathrm{~g})$, medium $(9.80 \mathrm{~g})$ and heavy (10.76 g) eggs as $30.0 \%, 20.4 \%$ and $22.7 \%$, respectively. In another study, which considered the egg shell colours, Farghly et al. (2015) reported weight loss ratio of $15.7 \%$ for white shells, $15.4 \%$ for brown dotted shells and $14.0 \%$ for dotted violet shells. The present weight loss ratios were greater than those of Romao et al. (2008), Genchev (2009), Nowaczewski et al. (2010), Nowaczki et al. (2012) and Aygun \& Sert (2013), but lower than those of Farghly et al. (2015).

Donofre (2017) reported weight loss ratios of low vibration for short duration, low vibration for long duration, high vibration for short duration, high vibration for long duration and control treatments as $6.0 \%$, $6.5 \%, 10.0 \%, 14.8 \%$ and $6.0 \%$, respectively.

\section{Conclusions}

Relative weight loss varied significantly with storage duration. Hatchability of fertile eggs varied with storage duration and transportation, but only the effects of storage duration $\mathrm{x}$ transportation distance interaction were found to be significant $(P<0.05)$. Discarded chick ratios also varied with the treatment groups, but only the storage duration $\mathrm{x}$ transportation distance interaction was found to be highly significant, 
while the effects of storage duration on weight loss ratios throughout the embryonic development were found to be significant.

\section{Acknowledgments}

This research is summarized from the master's thesis prepared by Ali Günenç, Mustafa Kemal University, Institute of Science, Department of Animal Science. This thesis has been prepared by Assoc. Dr. Gülşen Çopur Akpinar consultancy. In addition, the study was supported by the Scientific Research Project Unit of Hatay Mustafa Kemal University, Turkey (Project number: 15580).

\section{Conflict of Interest Declaration} No conflict of interest.

\section{References}

Adeyanju, T.M., Abiola, S.S., Adegbite, J.A. \& Adeyanju, S.A., 2014. Effect of egg size on hatchability of Japanese quail (coturnix coturnix japonıca) chicks, J. Emer. Trend Engin. Appl. Sci. (JETEAS) 5, 133-135.

Alasahan, S., Copur Akpinar, G., Canogullari, S. \& Baylan, M., 2016. The impact of eggshell colour and spot area in Japanese quails: I. Eggshell temperature during incubation and hatching results. R. Bras. Zootec. 45, 219-229. Doi:10.1590/S1806-92902016000500003.

Anonymous, 2016. Association of the European poultry breeders. Available from: www.valobiomedia.com/content/epb_air_cargo_guide.pdf. Accessed 04 April 2016.

Aygun, A. \& Sert, D., 2013. Effects of prestorage application of propolis and storage time on eggshell microbial activity, hatchability, and chick performance in Japanese quail (Coturnix coturnix japonica) eggs, Poult. Sci. 92, 3330-3337.

Aygun, A., Sert, D. \& Copur, G., 2012. Effects of propolis on eggshell microbial activity, hatchability, and chick performance in Japanese quail (Coturnix coturnix japonica) eggs. Poult. Sci. 91, 1018-1025. Doi:10.3382/ps.2011-01944

Baylan, M., Canogullari, S., Ayasan, T. \& Copur, G., 2011. Effects of dietary selenium source, storage time, and temperature on the quality of quail eggs. Biol. Trace Elem. Res. 143, 957-964. Doi: 10.1007/s12011-010- 8912-x

Butcher, G.D. \& Nilipour, A.H., 2016. Numbers for successful poultry production. www.https://edis.ifas.ufl.edu/pdffiles/VM/VM09800.pdf (verified 12 October 2016).

Copur, G., Baylan, M. \& Canogullari, S., 2010. Egg weight, but not shape index, determines hatchability in Japanese quails (Coturnix coturnix japonica). J. Anim. Vet. Adv. 9, 1890-1895.

Copur Akpinar, G., Alasahan, S. \& Ayasan, T., 2017. Selected traits of hatched and unhatched eggs and growth performance of yellow Japanese quails. Braz. J. Poult. Sci. 19, 527-536. Doi: 10.1590/1806-9061- 2016-045

Daikwo, S.I., Dim, N.I. \& Momoh, M.O., 2011. Hatching characteristics of Japanese quail eggs in a tropical environment. Int. J. Poult. Sci. 10, 876-878.

Dere, S., İnal, Ş., Garip, M., Çağlayan, T. \& Tilki, M., 2005. Japon bıldırcınlarında (Coturnix coturnix japonica) kuluçkaöncesi yumurta ağırlık kaybı ilr yumurta ağırlığı ve civciv çıkış ağırlığı arasındaki ilişkiler, Vet. Bil. Derg. 21, 5-7. (in: Turkish)

Dereli-Fidan, E., Turkyilmaz, M.K. \& Nazligul, A., 2012. The effect of different storage and fumigation lengths on hatchability and hatching weight Japanese quail (Coturnix coturnix japonica), J. Anim. Vet. Adv. 11, 1400-1404.

Donofre, A.C., Silva, I.J.O., Nazareno, A.C. \& Ferreira, I.E.D.P., 2017. Mechanical vibration in the transport of hatching eggs and the losses caused in the hatch and quality of broiler chicks. J. Agr. Engine. XLVIII: 593, 36-41. Doi:10.4081/jae.2017.593

Dudusola, I.O., 2009. Effects of storage methods and length of storage on some quality parameters of Japanese quail eggs. Tropicultura 27, 45-48.

Farghly, M.F.A., Mahrose, K.H.M.A. \& Abou-Kassem, D.E., 2015. Pre and post hatch performance of different Japanese quail egg colors incubated under photo stimulation. Asian J. Poult. Sci. 9, 19-30. Doi: 10.3923/ajpsaj.2015.19.30

Fidan, E.D., 2012. Türkiye'de Çiftlik Hayvanları ile İlgili Refah Uygulamaları. In: 'Proceedings of Uluslararası Türk ve Akraba Topluluklar Zootekni Kongresi'. pp. $79-87$ (in Isparta Turkey).

Genchev, A., 2009. Influence of hatching eggs storage period upon the incubation parameters in Japanese quails. J. Cent. Eur. Agri. 10, 167-174. Doi:10.22161/ijeab

Islam, M.S., Faruque, S., Khatun, H. \& Islam, M.N., 2014. Effects of quail genotypes on hatchability traits, body weight and egg production. J. Bangladesh Acad. Sci. 38, 219-224. Doi:10.3329/jbas.v38i2.21346

Lacin, E., Coban, O. \& Sabuncuoglu, N., 2008. Effects of egg storage material and storage period on hatchability in Japanese quail. Asian-Austral. J. Anim. Sci. 21, 1183-1188. Doi:10.5713/ajas.2008.70695

Mitchell, M.A. \& Kettlewell, P.J., 1998. Physiological stress and welfare of broiler chickens in transit solutions not problems. Poult. Sci. 77, 1803-1814. Doi:10.1093/ps/77.12.1803

Mohammadzadeh, S., Karimian, H., Khosravina, H. \& Shahbazı, F., 2015. Effect of different mechanical vibration on blood parameters of one day old broiler chicken. Anim. Res. Int. (ARI). 12, 2143-2149.

Moraes, T.G.V., Romao, J.M., Teixeira, R.S.C. \& Cardoso, W.M., 2008. Effects of egg position in artificial incubation of Japanese quail eggs (Coturnix japonica). Anim. Reprod. 5, 50-54. 
Mukai, H., Hironaka, M., Tojo, S. \& Nomakuchi, S., 2014. Maternal vibration: An important cue for embryo hatching in a subsocial shield bug. PLOS ONE 9, 1-7. www.plosone.org. Doi:10.1371/journal.pone.0087932

Nowaczewski, S., Witkiewicz, K., Kontecka, H., Krystianiak, S. \& Rosinski, A., 2010. Eggs weight of Japanese quail vs. eggs quality after storage time and hatchability results. Arch. Anim. Breed. 53, 720-730. Doi:10.5194/aab-53- 7202010

Nowaczewski, S., Kontecka, H. \& Rosiński, A., 2012. Effect of Japanese quail eggs location in the setter on their weight loss and eggshell temperature during incubation as well as hatchability results. Eur. Poult. Sci. 76,168-175.

Othman, R.A., Amin, M.R. \& Rahman, S., 2014. Effect of egg size, age of hen and storage period on fertility, hatchability, embryo mortality and chick malformations in eggs of Japanese quail (Coturnix coturnix japonica), IOSR. J. Agric. Vet. Sci. 7, 101-106.

Petek, M. \& Dikmen, S., 2004. The effect of prestorage incubation of quail breeder eggs on hatchability and subsequent growth performance of progeny. Anim. Res. 53, 527-534.

Pierce, C.D., Singh, S.P. \& Burgess, G., 1992. Comparison of leafspring with air-cushion trailer suspension in the transport environment. Packag. Technol. Sci. 5, 11-15. Doi:10.1002/pts.2770050104

Premavalli, K., Thyagaraja, D., Ashok, A., Sangilmadan, K., Omprakash, A.V. \& Babu, M., 2016. Effect of short term egg storage period on hatching performance of Japanese quail. Indian J. Vet. 93, 21-23.

Racine, V., 2013. Embryo project encylopedia. Available at http://embryo.asu.edu/handle/10776/6045. Accessed 20 September 2017.

Romao, J.M., Moraes, T.G.V., Teixeira, R.S.C., Cardoso, W.M. \& Buxade, C.C., 2008. Effect of egg storage length on hatchability and weight loss in incubation of egg and meat type Japanese quails. Braz. J. Poult. Sci. 10, $143-147$. Doi: 10.1590/S1516-635X2008000300001

Roriz, B.C., Sgavioli, S., Garcia, R.G., Naas, I.A., Domingues, C.H.F., Caldara, F.R., Rombola, L.G., Ayla, C.M. \& Bernnecke, K., 2016. Storage period affects weight loss of Japanese quail. Braz. J. Poult. Sci. 18, 589-592. Doi:10.1590/1806-9061- 2015-178

Sadeghi, R., Pakdel, A. \& Shahrbabak, M.M., 2013. Effects of divergent selection and egg status in artificial incubator on reproductive trait in Japanese quail. World Appl. Sci. J. 24, 463-466. Doi:10.5829/idosi.wasj.2013.24.04.2914

Schwartzkopf-Genswein K.S., Faucitano L., Dadgar S., Shand P., González L.A. \& Crowe T.G., 2012. Road transport of cattle, swine and poultry in North America and its impact on animal welfare, carcass and meat quality: A review. Meat Sci. 92, 227-243.

Seker, I., Kul, S. \& Bayraktar, M., 2005. Effects of storage period and egg weight of Japanese quail eggs on hatching results (short communication). Arch. Anim. Breed. 5, 518-526. Doi:10.5194/aab-48- 518-2005.

Shannon, S.G., Moran, A.W., Shackelford, L.C. \& Mason, K.T., 1994. Effect of vibration frequency and amplitude on developing chicken embryos. United States Army Aeromedical Research Laboratory Fort Rucker, USAARL Report No. 95-1, Alabama.

Singh, S.P., 1991. Vibration levels in commercial truck shipments as a function of suspension and payload. ASAE Paper 20, 466-469, 1991. Doi: 10.1520/JTE11941J

SPSS 20.0., 2012. Statistical Package for Social Sciences. United States, IBM.

Sreenivasaiah, P.V. \& Ramappa, B.S., 1985. Influence of mating ratio and pre-incubation storage on fertility and hatchability of Japanese quail. World Rev. Anim. Prod. 21, 25-28.

Torma, T. \& Kovacsne, K.G., 2012. Effects of mechanical Impacts on hatchability of broiler breeders. J. Agr. Sci. Technol. A. 4, 535-540.

Tullett, S., 2009. Investigating hatchery practice. Available at: http://en.aviagen.com/assets/Tech_Center/Ross_Tech_Articles/RossTechInvestigatingHatcheryPractice.pdf (verified 25 October 2017).

Uddin, M.S., Paul, D.C. \& Huque, Q.M.E., 1994. Effect of egg weight and pre-incubation holding periods on hatchability of Japanese quail eggs in different seasons. Asian-Austral. J. Anim. Sci. 7, 499-503.

Wilson, H.R., 1991. Effect of egg size on hatchability, chick size, and posthatching growth. In: Tullet, S.G. (ed). Avian Incubation. pp. 279-283. Butterworth-Heinemann, Cambridge. 